\title{
Plane of nutrition before and after 6 months of age in Holstein- Friesian bulls: I. Effects on performance, body composition, age at puberty, and postpubertal semen production
}

\author{
C. J. Byrne, ${ }^{\star} \dagger$ S. Fair, $\ddagger$ A. M. English, ${ }^{\star} \ddagger$ M. Cirot, $\S$ C. Staub,§ P. Lonergan, $\dagger$ and D. A. Kenny ${ }^{*} \dagger^{1}$ \\ ${ }^{*}$ Animal and Bioscience Department, Teagasc, Dunsany, Co. Meath, C15 PW93, Ireland \\ †School of Agriculture and Food Science, University College Dublin, Belfield, Dublin 4, Dublin, D04 F6X4, Ireland \\ łLaboratory of Animal Reproduction, Department of Biological Sciences, University of Limerick, Limerick, V94 T9PX, Ireland \\ §UE1297 PAO, Unité Expérimentale Physiologie Animale de l'Orfrasière, INRA, Nouzilly 37380, France
}

\begin{abstract}
The aim of this study was to examine the effect of plane of nutrition (1) during the first 6 mo of life and (2) from 6 mo of age to puberty on early growth characteristics, age at puberty, and postpubertal semen production in Holstein-Friesian bulls. Holstein-Friesian bull calves $(\mathrm{n}=83)$ with a mean (standard deviation) age and body weight of 17 (4.4) d and $52(6.2) \mathrm{kg}$, respectively, were assigned to a high (Hi) or low (Lo) plane of nutrition for the first 6 mo of life. The Hi and Lo calves received 1,200 and $450 \mathrm{~g}$ of milk replacer, respectively; Hi calves were fed concentrate ad libitum and Lo were fed a maximum of $1 \mathrm{~kg}$ concentrate daily, and concentrate allowances remained the same after weaning. At 24 wk of age, bulls were reassigned within treatment to either remain on the same diet or to switch to the opposite diet until puberty, resulting in 4 treatment groups: Hi-Hi, Hi-Lo, Lo-Lo, and Lo-Hi. After puberty, all bulls were fed a moderate plane of nutrition until $60 \mathrm{wk}$ of age; thereafter, the diet was ad libitum concentrates until slaughter at 72 wk of age. Bulls were weighed weekly before weaning and every 2 wk after weaning. Scrotal circumference (SC) was measured every 2 wk, beginning at 15 wk of age. Beginning at a $\mathrm{SC}$ of $24 \mathrm{~cm}$, electro-ejaculation was carried out every 2 wk to establish the onset of puberty. Semen collection continued monthly after puberty. Thermal images of the scrotum were taken monthly from 28 to 36 wk of age. Scrotal skin thickness (SST) was measured monthly (from 16 wk of age to puberty) using a digital calipers. Bulls on the Hi diet had a higher scrotal temperature and SST at each time point than those on the Lo diet. Average daily gain (ADG) was greatest in Hi-Hi bulls, with Hi-Lo and Lo-Hi having similar ADG
\end{abstract}

\footnotetext{
Received August 21, 2017.

Accepted January 2, 2018.

${ }^{1}$ Corresponding author: david.kenny@teagasc.ie
}

but both being greater than Lo-Lo. Bulls on the Hi diet pre- 6 mo of age were younger at puberty, regardless of diet offered post- 6 mo of age. Bulls offered a Hi diet post-6 mo were heavier at puberty. Neither scrotal temperature nor dietary treatment affected postpubertal semen production variables. In conclusion, a high plane of nutrition during the first 6 mo of age hastened the onset of puberty and the availability of saleable semen, regardless of plane of nutrition post- 6 mo of age.

Key words: semen quality, age at puberty, thermoregulation

\section{INTRODUCTION}

The widespread implementation of genomic selection in recent years has meant that sires used in AI are selected at younger ages than was previously possible through traditional progeny testing. Although this has the potential to accelerate genetic gain by reducing the generation interval (Berry et al., 2014), it has led to increased demand for semen from sires at a young age (de Roos et al., 2011). However, the reproductive potential of these young bulls is limited by the quantity and quality of semen that they can produce (Rawlings et al., 2008). Recent studies have reported that enhanced nutrition before $31 \mathrm{wk}$ of age leads to earlier onset of puberty in Holstein-Friesian bulls (Dance et al., 2015; Harstine et al., 2015), whereas restricting the diet of beef bulls before 26 wk of age delays age at puberty onset, which could not be reversed by an increase in the plane of nutrition from $27 \mathrm{wk}$ to $70 \mathrm{wk}$ of age (Brito et al., 2007a). In both studies conducted on Holstein-Friesian bulls (Dance et al., 2015; Harstine et al., 2015), postpubertal semen production was unaffected by diet, whereas a high plane of nutrition from 10 to $30 \mathrm{wk}$ in young beef bulls led to higher total daily sperm production at $74 \mathrm{wk}$ of age compared with those offered a control diet from 10 to 74 wk of age (Brito et al., 2007b). A similar response in terms of age at 
puberty to increased early life ADG was also observed in heifers (Cardoso et al., 2014). While reviewing the literature on sexual maturation of the bulls, Rawlings et al. (2008) noted that a dramatic increase in testicular growth occurs from approximately 24 wk of age. As it has been reported that scrotal circumference (SC) is linked to sperm production potential (Palasz et al., 1994), advancing scrotal growth in the period after 24 wk of age promotes optimum sperm production potential.

The implications of an elevated feeding regimen on scrotal fat accretion and testicular thermoregulation have been reviewed (Kastelic, 2014). Whereas greater BW gain is generally mirrored by increased testicular growth, within breed (Byrne et al., 2017), the degree of scrotal fat required to adversely affect sperm production has not been well defined. Rearing strategies that consistently advance puberty and sexual maturation are required if the supply of semen from young elite sires is to meet demand, particularly within the context of seasonal breeding systems when inseminations are typically concentrated in a 6 - to 8 -wk period. We hypothesized that increasing the early life plane of nutrition would (1) hasten age at puberty, and (2) increase subsequent semen production potential of Holstein-Friesian bulls. Thus, the aim of this study was to examine the effects of plane of nutrition during the first $6 \mathrm{mo}$ of life and from $6 \mathrm{mo}$ of age to puberty on early growth characteristics, age at puberty, and postpubertal semen production potential of HolsteinFriesian bulls.

\section{MATERIALS AND METHODS}

All animal procedures performed were conducted under experimental license from the Irish Department of Health and Children (license number B100/4516). Protocols were developed in accordance with the Cruelty to Animals Act (Ireland 1876, as amended by European Communities regulations 2002 and 2005) and the European Community Directive 86/609/EC.

\section{Animal Management}

Autumn-born Holstein-Friesian bull calves $(\mathrm{n}=83)$ with a mean $( \pm \mathrm{SD})$ age and $\mathrm{BW}$ of $17(4.4) \mathrm{d}$ and $52(6.2) \mathrm{kg}$, respectively, were blocked by age, BW, sire, and farm of origin and assigned to a high (HPN) or low (LPN) plane of nutrition for the first 6 mo of life. Bulls assigned to HPN $(\mathrm{n}=37)$ and LPN $(\mathrm{n}=$ 46) received 1,200 and $450 \mathrm{~g}$ of milk replacer (Table 1 and Supplemental Table S1; https://doi.org/10.3168/ jds.2017-13719), respectively. The HPN bulls were fed concentrate ad libitum and the LPN bulls were offered a maximum of $1 \mathrm{~kg}$ of concentrate daily (Table 1 and Supplemental Table S2; https://doi.org/10.3168/jds .2017-13719). All animals were offered hay (Table 1 and Supplemental Table S3; https://doi.org/10.3168/ jds.2017-13719) as a source of roughage and had ad libitum access to water. Mineral and vitamin supplementation was also provided (Supplemental Table S2). Diets were designed using NRC (2001) guidelines. Bulls were individually fed using an electronic feeding system (Vario, Forster-Technik, Engen, Germany) before weaning and were penned thereafter according to treatment until turnout to pasture at $24 \mathrm{wk}$ of age. Bulls were rotationally grazed in their respective treatment groups until the onset of puberty, at which bulls were rehoused in slatted-floor pens. Bulls were offered preweaning diets for a minimum of $56 \mathrm{~d}$ and were weaned once they were consuming $1 \mathrm{~kg}$ of concentrates for 3 consecutive days. After weaning, HPN bulls were fed ad libitum concentrates and LPN bulls received $1 \mathrm{~kg}$ of concentrate daily; both groups were offered hay to appetite. At 24 wk of age, bulls were reassigned, within treatment, to either remain on the same diet or to switch to the opposite diet until puberty. This resulted in 4 groups: HPN-HPN (Hi-Hi), HPN-LPN (Hi-Lo), LPN-LPN (Lo-Lo), and LPN-HPN (Lo-Hi), with $\mathrm{n}=$ 19, 18, 22 and 24, respectively. Bulls were turned out to high-quality pasture at 26 wk of age, where $\mathrm{Hi}-\mathrm{Hi}$ and Lo-Hi bulls received grass (Table 1 and Supplemental Table S3; https://doi.org/10.3168/jds.2017-13719) and concentrate ad libitum, whereas Lo-Lo and Hi-Lo bulls received grass to appetite plus $0.5 \mathrm{~kg}$ of concentrate daily. After puberty, bulls were fed a moderate plane of nutrition consisting of $4 \mathrm{~kg}$ of concentrates and grass silage (Table 1 and Supplemental Table S3) ad libitum until 60 wk of age. From 60 wk of age, all animals were fed concentrate ad libitum plus $5 \mathrm{~kg}$ of grass silage, until slaughter at 72 wk of age.

Table 1. Crude protein and energy values of feedstuffs offered (mean \pm SEM)

\begin{tabular}{lll}
\hline Feedstuff & $\begin{array}{c}\text { CP } \\
(\mathrm{g} / \mathrm{kg} \text { of DM })\end{array}$ & $\begin{array}{c}\text { Gross energy } \\
(\mathrm{MJ} / \mathrm{kg} \text { of DM })\end{array}$ \\
\hline Concentrate & $167.9 \pm 1.86$ & $16.1 \pm 0.03$ \\
Pre-puberty & $106.6 \pm 2.29$ & $15.8 \pm 0.04$ \\
Post-puberty & $107.5 \pm 9.35$ & $16.1 \pm 0.08$ \\
Hay & $152.4 \pm 9.73$ & $16.1 \pm 0.07$ \\
Grass & $216.3 \pm 1.24$ & $20.3 \pm 0.56$ \\
Milk replacer ${ }^{1}$ & $122.2 \pm 9.4$ & $16.3 \pm 0.08$ \\
Silage & & \\
\hline
\end{tabular}

${ }^{1}$ Analyzed by acid hydrolysis. 


\section{Measurements}

Animals were weighed weekly before weaning and every 2 wk after weaning. Beginning at 15 wk of age, SC was measured every 2 wk using a scrotal measuring tape (Ideal Instruments, Neogen, Winchester, KY). When an SC of $24 \mathrm{~cm}$ was attained, electro-ejaculation (Pulsator, Lane Manufacturing, Denver, CO) commenced. Electro-ejaculation was carried out in accordance with manufacturer's guidelines; the "program" function was used, which applies $4 \mathrm{~s}$ of stimulation followed by $4 \mathrm{~s}$ of rest with increasing voltage and ending at step 7 (steps 0-9). The program was ended when ejaculation ceased or step 7 was reached, whichever occurred first. The "program" function was used previously by Falk et al. (2001) in 2-yr-old bulls and was deemed to provide adequate stimulation for optimum ejaculation. Puberty was deemed to have been reached when an ejaculate containing a minimum of $50 \times 10^{6}$ sperm with $>10 \%$ progressive motility (PLM) was collected (Wolf et al., 1965); this was confirmed by a second ejaculate $2 \mathrm{wk}$ later. Semen was collected into a $15-\mathrm{mL}$ tube and volume was recorded. Within 10 min of collection, PLM was assessed using phase contrast microscopy $(400 \times)$ incorporating a heated stage and counting 100 sperm (2 counts of 50 sperm cells) per sample (Holden et al., 2017). Sperm concentration was assessed using a hemocytometer. After puberty, semen was collected monthly, using the same electro-ejaculation technique and was analyzed as described above, with the addition of nigrosin-eosin staining (Supplemental Figure S1; https://doi.org/10.3168/jds.2017-13719) to assess age at sexual maturity, defined as $\geq 30 \%$ PLM and $\geq 70 \%$ normal morphology (Brito et al., 2004).

Linear body measurements (Campion et al., 2009) began at $16 \mathrm{wk}$ of age and were taken every $8 \mathrm{wk}$ on each animal to provide a quantitative measurement of skeletal development. The measurements taken included height at the withers, length of the back, chest circumference, chest depth, and width of the pelvis. Bulls were ultrasonically scanned at the same time points as linear measurements, beginning at $24 \mathrm{wk}$ of age. A dynamic imaging real-time scanner (Dynamic Imaging Concept MLV, Livingston, Scotland) was used to measure longissimus dorsus depth at the third lumbar vertebra and fat depth at the third lumbar vertebra, 13th thoracic rib, and rump on the right side of the animal, as previously described (Conroy et al., 2010).

Thermal images of the scrotum were taken on 3 occasions at monthly intervals, from 28 to 36 wk of age, using a thermal imaging camera (FLIR E60, FLIR Systems Inc., Wilsonville, OR). Average scrotal skin surface temperature and gradient (difference in temperature between the testicular vascular cone and caudal epididymal region) were recorded (Menegassi et al., 2015) using FLIR tools+ (FLIR Systems Inc.). All bulls were standing on a concrete-floored collecting yard for a minimum of 15 min before image capture. Any bull that had a wet or dirty scrotum was dried or cleaned as well as possible; if this could not be carried out adequately, bulls were excluded from that month of image capture (bulls excluded: $\mathrm{n}=\mathrm{Hi}-\mathrm{Hi}=2$; Hi-Lo $=2 ; \mathrm{Lo}-\mathrm{Lo}=0 ; \mathrm{Lo}=\mathrm{Hi}=3)$. All measurements were taken indoors avoiding exposure to direct sunlight. Scrotal skin thickness (SST) was measured monthly from 16 wk of age to puberty using a digital calipers (TT caliper, Hauptner-Herbolz, Solingen, Germany) adapted from the method of Edwards et al. (1955). Briefly, scrotal skin was lifted away from the testes and 2 measurements were taken from each side of the scrotum. The average of the 4 measurements was divided by 2 (to account for overlap of skin) to obtain the SST.

At slaughter, both testes were removed, epididymides were separated from testes, and each tissue type was weighed separately to obtain paired testes and paired epididymal weights. Testicular parenchyma samples were collected, fixed in formalin, and embedded in paraffin. One testicular piece was prepared for each bull. Nuclear volume density (percentage of parenchyma occupied by nuclei of each cell type) was assessed by the point-counting method (Johnson, 1985) of $5-\mu \mathrm{m}$ tissue sections stained with hematoxylin and eosin at $1,000 \times$ magnification by bright-field light microscopy to determine the various cell types. Cell types of interest were Sertoli cells, pachytene and diplotene primary spermatocytes (from stage VI to stage III), and round spermatids (from stage $\mathrm{V}$ to stage $\mathrm{I}$ ) according to bull seminiferous epithelium cycle (Amann, 1970; Supplemental Figure S2; https://doi.org/10.3168/jds.2017 -13719).

\section{Feed Sample Collection and Analysis}

Samples of all feeds offered were collected weekly and stored at $-20^{\circ} \mathrm{C}$. Weekly samples were then combined into monthly samples and sub-sampled. A sub-sample was used to determine DM content by drying the ration and grass at $98^{\circ} \mathrm{C}$ for $16 \mathrm{~h}$ and silage at $85^{\circ} \mathrm{C}$ for $16 \mathrm{~h}$. A second sub-sample was dried at $40^{\circ} \mathrm{C}$ for $48 \mathrm{~h}$ for chemical analysis. Both silage and ration samples were milled through a 1-mm screen and subsequently analyzed for $\mathrm{CP}, \mathrm{ADF}, \mathrm{NDF}$, ash, ether, and gross energy. Crude protein was determined using the method of Sweeney (1989) with a Leco FP 528 nitrogen analyzer (Leco Instruments UK Ltd., Cheshire, UK). Acid detergent fiber and NDF were determined using the 
Ankom method (Ankom Technologies, Macedon, NY). Ash was determined after ignition of a known weight of ground sample in a furnace (Carbolite Gero, Hope, UK) at $550^{\circ} \mathrm{C}$ for $4 \mathrm{~h}$. The gross energy of milk powder, concentrate, and silage samples was determined using an adiabatic bomb calorimeter (Parr Instruments, Moline, IL).

\section{Statistical Analysis}

Data were analyzed using appropriate procedures of SAS software (version 9.3, SAS Institute, Inc. Cary, NC). Data were tested for normality of distribution (UNIVARIATE procedure) and, where appropriate, transformed to the power of lambda (TRANSREG procedure). Data were analyzed using ANOVA (MIXED procedure). Differences in individual least squares means were evaluated using the Tukey-Kramer adjustment. Diet, block, sampling time, and their interactions were included in the model. The interaction term if not statistically significant $(P>0.05)$ was subsequently excluded from the final model. The covariance matrix was determined for each variable by examining the Bayesian information criterion (BIC; smaller is better) value. Animal was the experimental unit for analysis of ADG, age at puberty, and sexual maturation. Sampling time (week of collection) was included in the statistical models as a repeated term for weight, SC, ultrasound and body measurements, SST, scrotal skin temperature, and postpubertal semen production. For semen production between 36 and 60 wk of age, the prepubertal samples collected every 2 wk were averaged and used as one monthly data point. All results are presented as mean \pm standard errors of the mean, unless stated otherwise.

\section{RESULTS}

The effect of diet on BW is presented in Figure 1. Bulls offered the HPN in the pre- 6 mo period, grew faster than those on the LPN during the pre-weaning and weaning-to- 6 mo periods $(P<0.001$; Table 2$)$, resulting in a difference in ADG between the 2 diets of 380 g per day $(P<0.001)$. A pre $\times$ post diet interaction for post-6 mo ADG was detected $(P<0.001$; Table $2)$. This was manifested as Hi-Lo bulls having a lower ADG than Lo-Lo bulls, whereas growth accelerated in the Lo-Hi bulls to the same rate as that of the Hi-Hi group after 6 mo. Overall ADG (from 2 wk of age to puberty) was highest in Hi-Hi bulls and lowest in Lo-Lo bulls $(P<0.001)$. The Hi-Lo and Lo-Hi bulls were not different from one another but ADG was lower than for Hi-Hi $(P<0.001)$ and higher than Lo-Lo bulls $(P$
$<0.001)$. Diet affected BW during both the pre- and post-6 mo periods $(P<0.001$; Figure 1$)$; bulls allowed a constant HPN achieved the greatest BW at all time points examined.

The effect of plane of nutrition on SC was consistent with that of BW with HPN bulls having larger SC pre6 mo $(P<0.001$; Figure 1$)$. Post-6 mo, Hi-Hi bulls had a larger SC than Lo-Lo bulls $(P<0.001$; Figure 1 ), whereas Lo-Hi bulls had a larger SC than Lo-Lo bulls $(P<0.01)$ but a smaller SC than Hi-Hi bulls $(P<0.001)$. The Hi-Lo bulls had a larger SC than Lo-Lo bulls $(P<0.001)$, but were not different from either Hi-Hi or Lo-Hi bulls. Pre- or post-6 mo diet did not affect any of the body measurements (Table 3 ). Height, length, chest depth, chest circumference, and pelvis width increased with increasing age $(P<0.001)$. There was a post- 6 mo diet $\times$ age interaction for rib, lumbar, and rump fat depth $(P<0.01)$. Bulls on a Hi diet post- 6 mo had greater rib fat depth at 8 and 10 mo of age than those on a Lo diet. Bulls on a Hi diet pre-6 mo had greater rib, lumbar, and rump fat depth $(P<0.01)$ than their counterparts offered a Lo diet during that time. Bulls offered a Hi diet pre- 6 mo had greater longissimus dorsus depth than Lo bulls at $6(P$ $<0.001$; Table 3), $8(P<0.001)$ and $10(P<0.05)$ months of age. We also observed a post- 6 mo diet $\times$ age interaction for longissimus dorsus depth $(P<0.001)$, which manifested as no difference between treatments at 6 mo of age followed by a greater longissimus dorsus depth for Hi than for Lo diet bulls at 8 and 10 mo of age $(P<0.001)$.

There was a pre- 6 mo diet $\times$ age interaction for SST $(P<0.001$; Figure 2): bulls on a Hi diet had greater SST than bulls on a Lo diet from 4 to 7 mo of age $(P$ $<0.001)$, after which there was no difference. There was a post- 6 mo diet $\times$ age interaction for SST $(P<$ 0.001 ), whereby post- 6 mo diet had no effect from 4 to $7 \mathrm{mo}$ of age, after which Hi bulls had a greater SST than Lo bulls at 8 and 9 mo of age $(P<0.001)$. This difference was no longer evident at 10 mo of age. Diet $\times$ month interactions were not detected for temperature gradient or average scrotal temperature (Figure 2). At recording of scrotal skin temperatures, environmental temperatures were 11,20 , and $12.5^{\circ} \mathrm{C}$ in May, June, and July, respectively. Scrotal temperatures were higher in June than in either May or July $(P<0.001)$, and temperatures recorded in May were higher than those recorded in July $(P<0.01)$. Pre-6 mo diet had no effect on temperature gradient or average scrotal skin temperature. Post- 6 mo of age, average scrotal temperature was lower for Hi than for Lo bulls $(P<0.01)$.

There was a pre- 6 mo $\times$ post- 6 mo diet interaction for age at puberty $(P=0.09$; Table 4$)$. Bulls on the Hi 
Table 2. Effect of plane of nutrition (high or low) on growth rate in Holstein-Friesian bulls (mean \pm SEM) before (pre) and after (post) 6 mo

\begin{tabular}{|c|c|c|c|c|c|c|c|}
\hline $\operatorname{ADG}(\mathrm{kg} / \mathrm{d})$ & \multicolumn{2}{|c|}{ High (pre) } & \multicolumn{2}{|c|}{ Low (pre) } & \multicolumn{3}{|c|}{ Significance } \\
\hline Pre-weaning & \multicolumn{2}{|c|}{$0.76 \pm 0.026^{\mathrm{a}}$} & \multicolumn{2}{|c|}{$0.57 \pm 0.029^{\mathrm{b}}$} & $* * *$ & - & - \\
\hline Pre- 6 mo & \multicolumn{2}{|c|}{$1.18 \pm 0.033^{\mathrm{a}}$} & \multicolumn{2}{|c|}{$0.58+0.027^{\mathrm{b}}$} & $* * *$ & - & - \\
\hline Post- 6 mo & $1.60 \pm 0.03^{\mathrm{a}}$ & $0.70 \pm 0.05^{\mathrm{b}}$ & $0.96 \pm 0.03^{\mathrm{c}}$ & $1.60 \pm 0.03^{\mathrm{a}}$ & $* * *$ & $* * *$ & $* * *$ \\
\hline Overall $^{1}$ & $1.24 \pm 0.02^{\mathrm{a}}$ & $0.84 \pm 0.02^{\mathrm{b}}$ & $0.57 \pm 0.03^{\mathrm{c}}$ & $0.96 \pm 0.03^{\mathrm{b}}$ & $* * *$ & $* * *$ & NS \\
\hline
\end{tabular}

${ }^{\mathrm{a}-\mathrm{C}}$ Values within a row with different superscripts differ significantly.

${ }^{1} \mathrm{ADG}$ from 2 wk of age until puberty.

*** $P<0.001$.
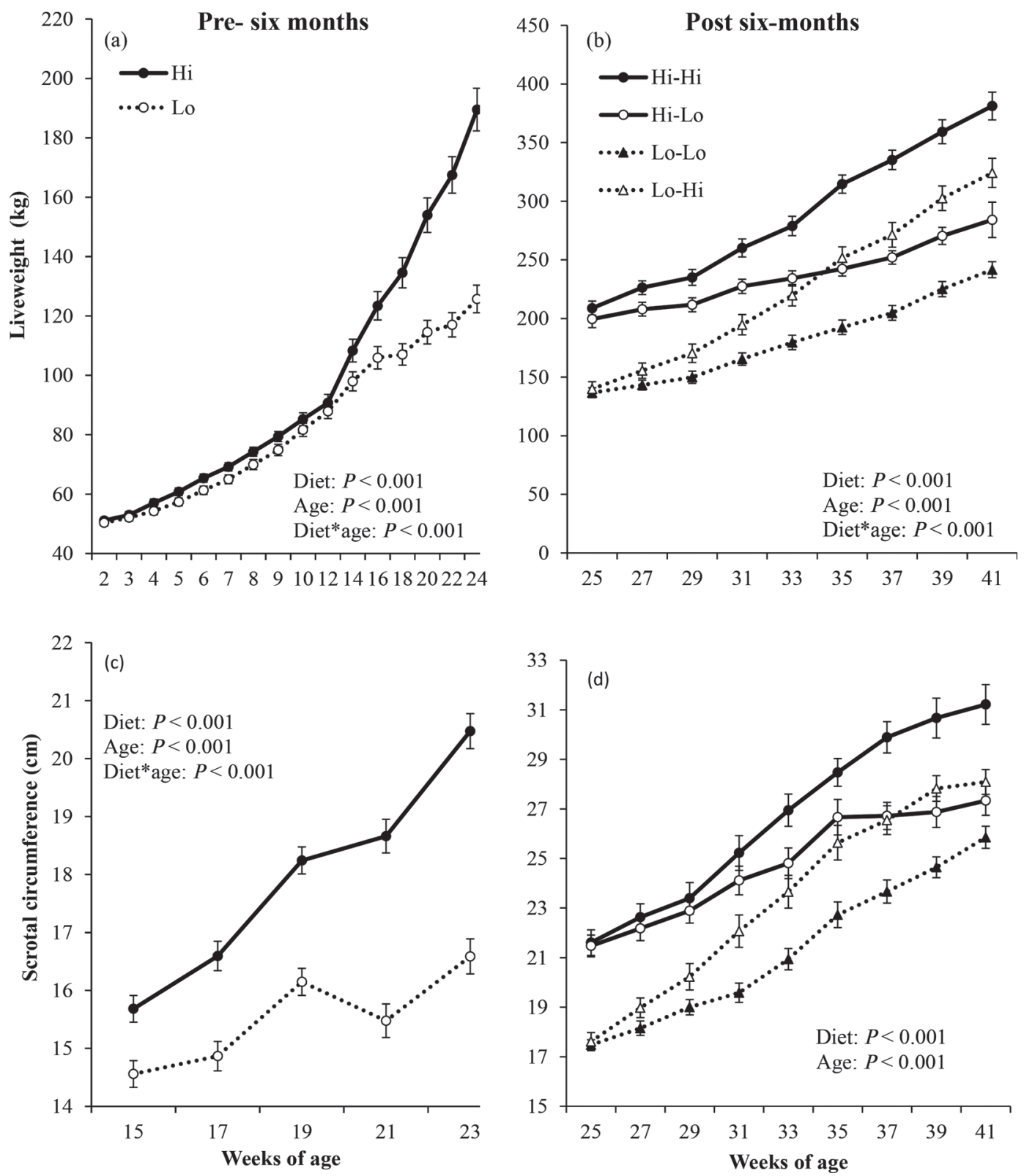

Figure 1. Effect of a high (Hi) or low (Lo) plane of nutrition offered pre-6 mo (a, c) or post-6 mo (b, d) of age on BW (a, b) and scrotal circumference $(\mathrm{c}, \mathrm{d})$ of Holstein-Friesian bulls ( $\mathrm{n}=\mathrm{Hi}-\mathrm{Hi}$ : 19; Hi-Lo: 18; Lo-Lo: 22; Lo-Hi: 24). Values are mean \pm SEM. 


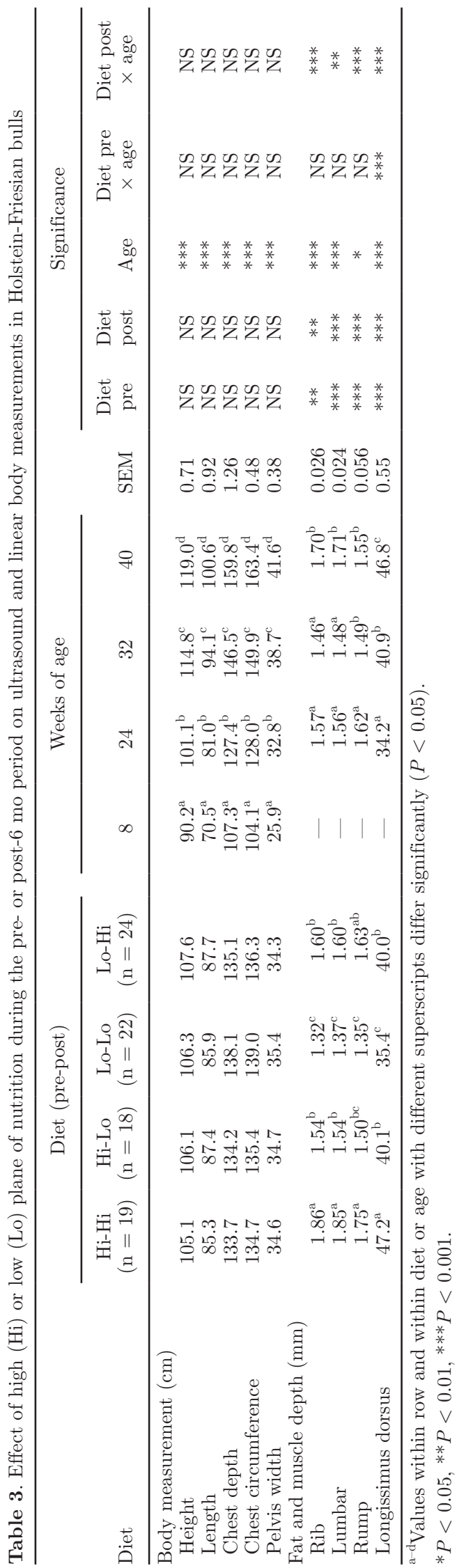

diet pre- 6 mo reached puberty approximately $30 \mathrm{~d}$ earlier than bulls on the Lo diet $(P<0.001)$. Importantly, the diet offered after 6 mo of age did not affect age at onset of puberty. There was no pre- 6 mo $\times$ post- 6 mo diet interaction for BW at puberty (Table 4). Bulls offered a Hi diet post-6 mo were heavier at puberty than bulls offered a Lo diet $(P<0.001)$, whereas BW at puberty was unaffected by pre- 6 mo diet. Bulls on a Hi diet pre-6 mo had a larger SC at puberty than bulls on a Lo diet $(P<0.05)$, whereas bulls offered a Hi diet post- 6 mo tended to have a larger SC at puberty $(P=$ $0.06)$. No pre- 6 mo $\times$ post- 6 mo diet interactions were observed for either age at sexual maturation or duration (days) from onset of puberty to sexual maturation (Table 4). An effect of pre-6 mo diet on age at sexual maturation $(P<0.001)$ was detected in line with age at puberty, with bulls offered a Hi diet pre- 6 mo being younger at sexual maturation than those on a Lo diet. Pre- or post-6 mo plane of nutrition did not affect the interval between puberty and sexual maturation.

No pre- 6 mo $\times$ post- 6 mo diet interactions were observed for semen volume, total sperm output, or PLM at 32 and 60 wk of age (Figure 3). Bulls offered a Hi diet had greater total sperm output between 32 and 60 wk of age $(P<0.01)$, with no effect of diet offered post- 6 mo of age. A tendency for a greater percentage of PLM in bulls offered a Hi diet pre- 6 mo was observed at $36 \mathrm{wk}$ of age $(P=0.09)$ and PLM was greater at $40 \mathrm{wk}$ of age $(P<0.01)$, resulting in a tendency for an interaction between diet pre- $6 \mathrm{mo}$ and age $(P=0.08)$. We observed an effect of age on volume, total sperm output, and PLM; both volume and total sperm output increased in a linear fashion, whereas PLM increased in a linear fashion until 48 wk of age and then plateaued until 60 wk of age. There was no pre- 6 mo $\times$ post- 6 mo interaction for either paired testes weight or paired epididymal weight when bulls were slaughtered at 72 wk of age (Table 4). Diet pre-6 mo affected paired testes weight $(P<0.05)$, being higher for bulls on a $\mathrm{Hi}$ diet pre- 6 mo of age. Diet offered post- 6 mo did not affect paired testes weight, nor was there an effect of pre- or post- 6 mo diet on paired epididymal weight. There was no effect of diet offered either pre- or post- 6 mo of age on the number of Sertoli cells, pachytene spermatocytes, or round spermatids (Table 4).

\section{DISCUSSION}

The main finding of this study was that HPN before 6 mo of age hastened puberty onset in Holstein-Friesian bulls. Despite leading to some compensatory growth, increasing plane of nutrition after 6 mo of age did not overcome delays in puberty onset incurred as a result of earlier growth retardation. 
(a)

$$
\begin{aligned}
& \longrightarrow \text { Hi-Hi } \\
& \longrightarrow \text { Hi-Lo } \\
& \cdots \triangle \cdot \text { Lo-Lo } \\
& \cdots \Delta \cdot \cdot \text { Lo-Hi }
\end{aligned}
$$
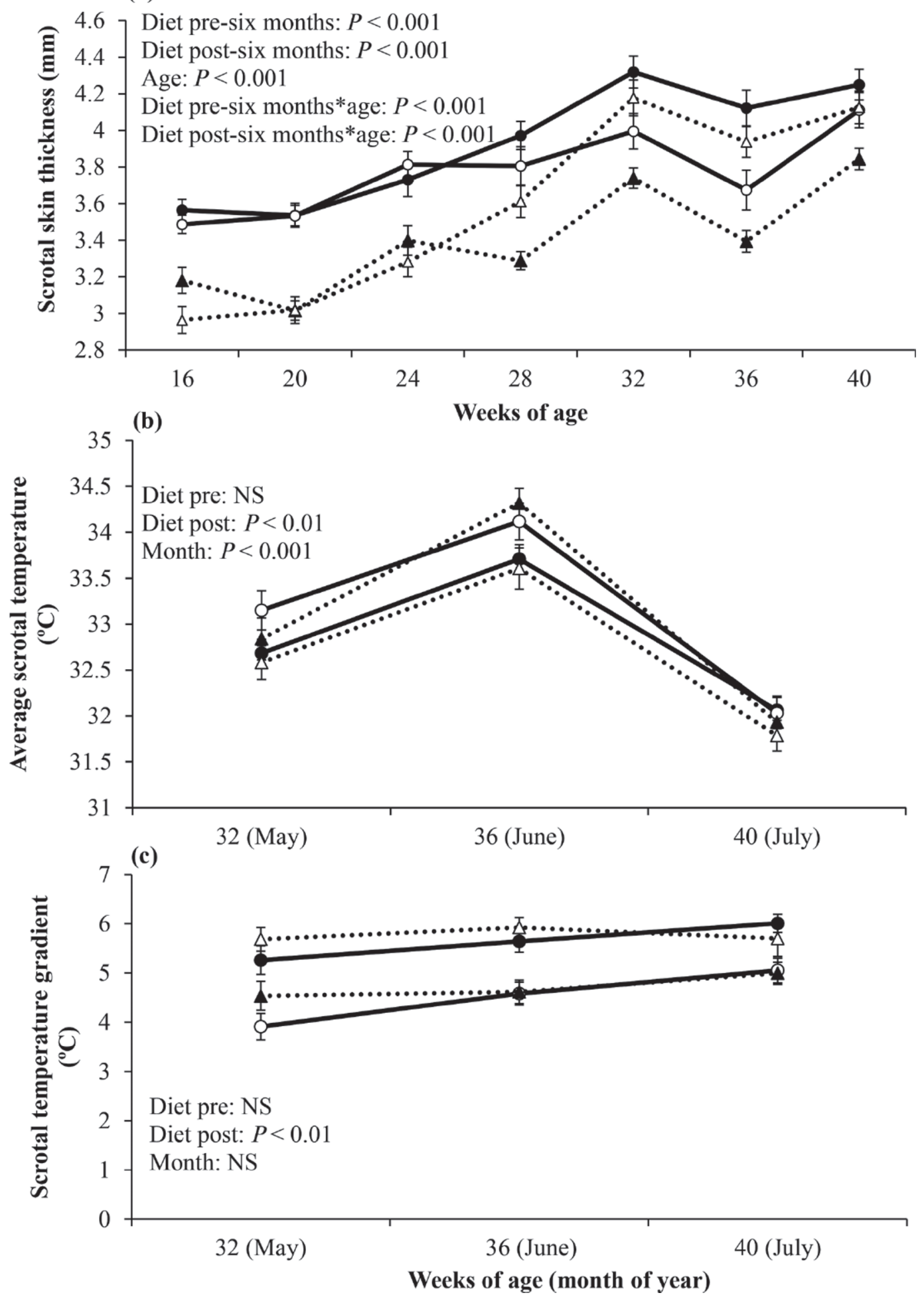

Figure 2. Effect of a high (hi) or low (Lo) plane of nutrition offered pre- or post-6 mo of age on scrotal skin thickness (a), average scrotal temperature (b), and scrotal temperature gradient (c) of Holstein-Friesian bulls (n = Hi-Hi: 19; Hi-Lo: 18; Lo-Lo: 22; Lo-Hi: 24). Values are mean \pm SEM. 


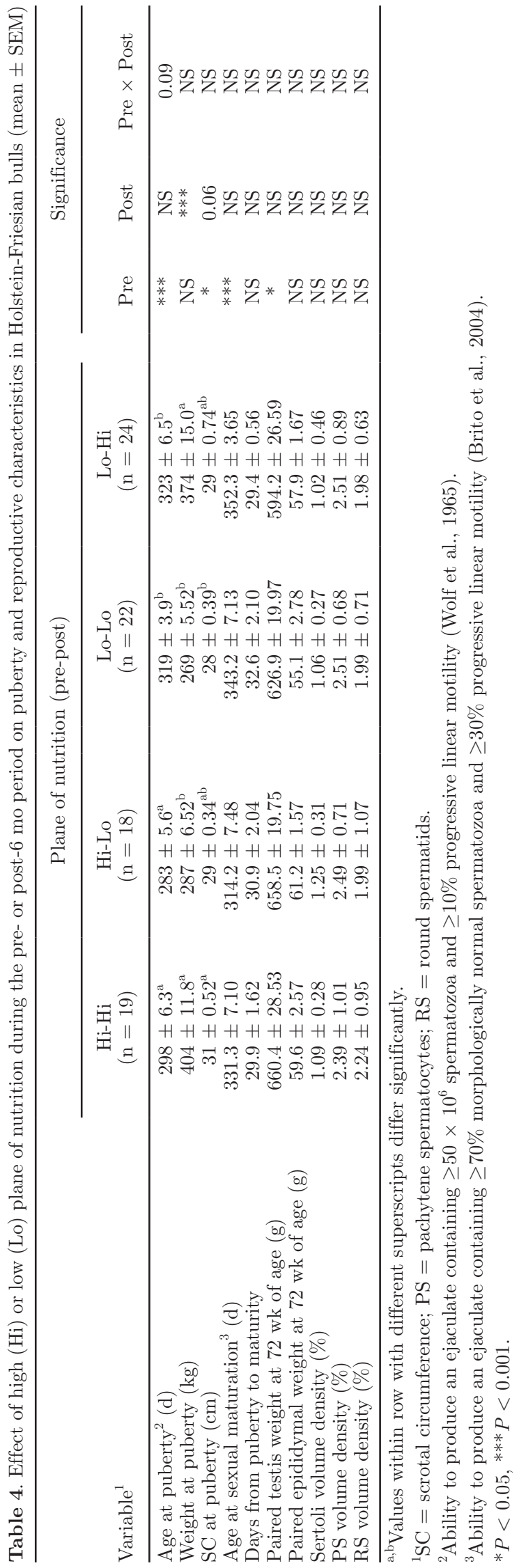

Barth et al. (2008), in a review of the published literature at the time, suggested that Angus and Angus $\times$ Charolais bulls need to achieve an ADG close to 1.2 $\mathrm{kg} / \mathrm{d}$ in early life to advance the onset of puberty. In the current study, an ADG of $0.96 \mathrm{~kg} / \mathrm{d}$ achieved during the first 6 mo of life by calves on an HPN was sufficient to advance puberty by $30 \mathrm{~d}$ compared with their LPN contemporaries, growing at $0.58 \mathrm{~kg} / \mathrm{d}$ during the same period. It is important to note that even when LPN calves achieved a moderate ADG of $\sim 0.60 \mathrm{~kg} / \mathrm{d}$ during the pre-weaning period and subsequently achieved very high growth rates of $\sim 1.6 \mathrm{~kg} / \mathrm{d}$, this was not sufficient to overcome delays incurred in puberty onset due to suboptimal early life performance. The effect of plane of nutrition on prevailing and latent BW response has been reported in heifer calves in an experimental model similar to that used here (Rodríguez-Sánchez et al., 2015). Positive relationships between early life BW gain and SC have also been reported in both dairy (Dance et al., 2015) and beef (Brito et al., 2007c) bulls. Previous studies have reported the utility of measuring $\mathrm{SC}$ as a predictor of puberty onset and have suggested a threshold size of $28 \mathrm{~cm}$ (Rawlings et al., 2008). In agreement with these findings, despite the large differences in growth trajectories, leading to substantial variation between the dietary groups in scrotal size and BW when puberty was achieved, SC at puberty seems to be highly conserved and averaged $29 \mathrm{~cm}$ for the bulls in this study.

The lack of an effect of diet on skeletal measurements was surprising and in contrast to the findings of Rodríguez-Sánchez et al. (2015), who observed that offering an LPN diet to Parda de Montaña $\times$ Brown Swiss heifers in the first 6 mo of life resulted in reduced height, chest circumference, and pelvic width, which was subsequently reversed following reallocation of heifers to an HPN diet after 6 mo of age, leading to greater body size at $15 \mathrm{mo}$ of age. Overall, a linear increase in all body measurements over time was observed, in agreement with the finding that skeletal growth is maximal during the first year of life in cattle (Wathes et al., 2014). In dairy-bred animals, fat deposition normally dominates tissue growth as age increases due to limited muscle growth potential (Hornick et al., 2000). However, Lo-Hi bulls did not become fatter or have a greater muscle depth than bulls that were on a Hi diet pre- 6 mo of age, highlighting the limited compensability of muscle and fat deposition in Holstein-Friesian bulls. Bulls on the Hi diet pre-6 mo had greater subcutaneous fat than Lo bulls at $6 \mathrm{mo}$, in line with the experimental design, suggesting that Hi bulls would have had greater fat and thus energy reserves when it is most important (early life), possibly leading to increased systemic concentrations of leptin (Byrne et al., 2018) which have been 


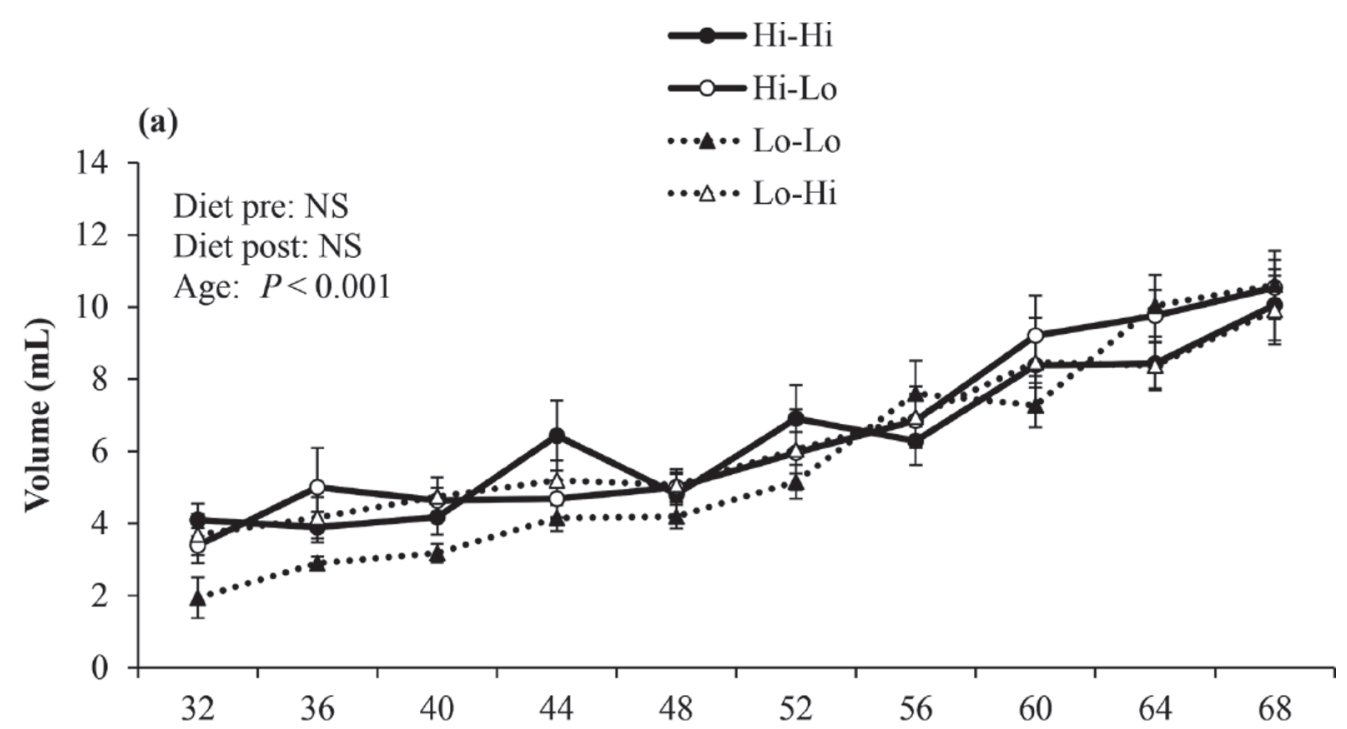

(b)

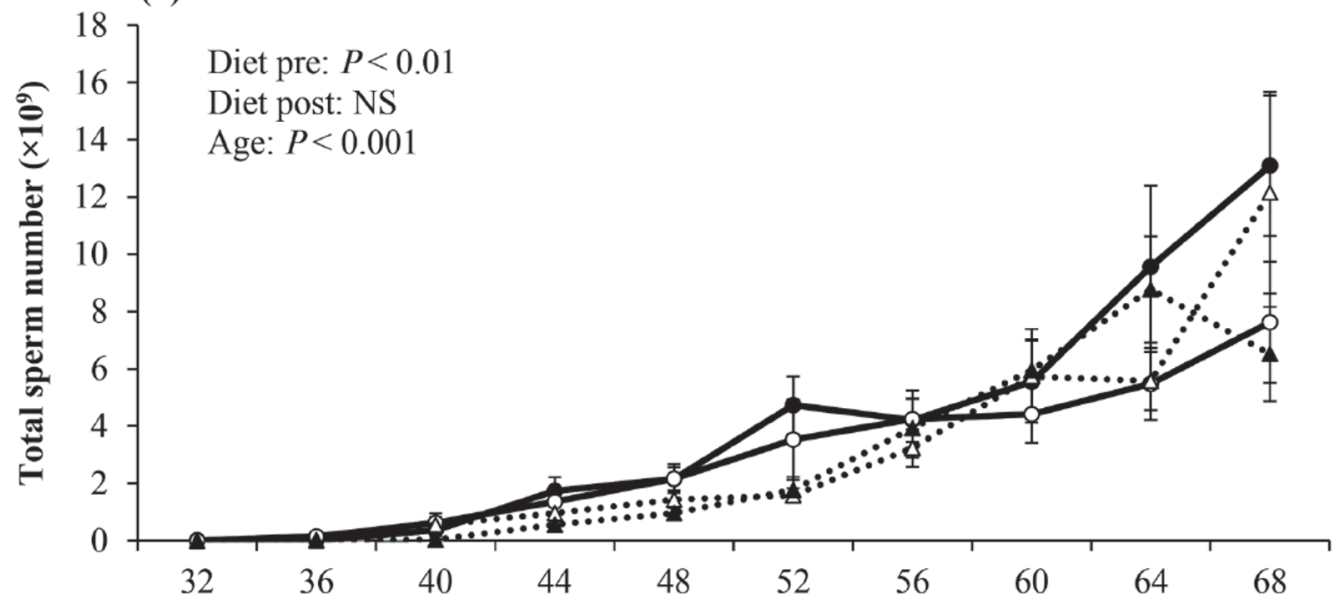

(c)

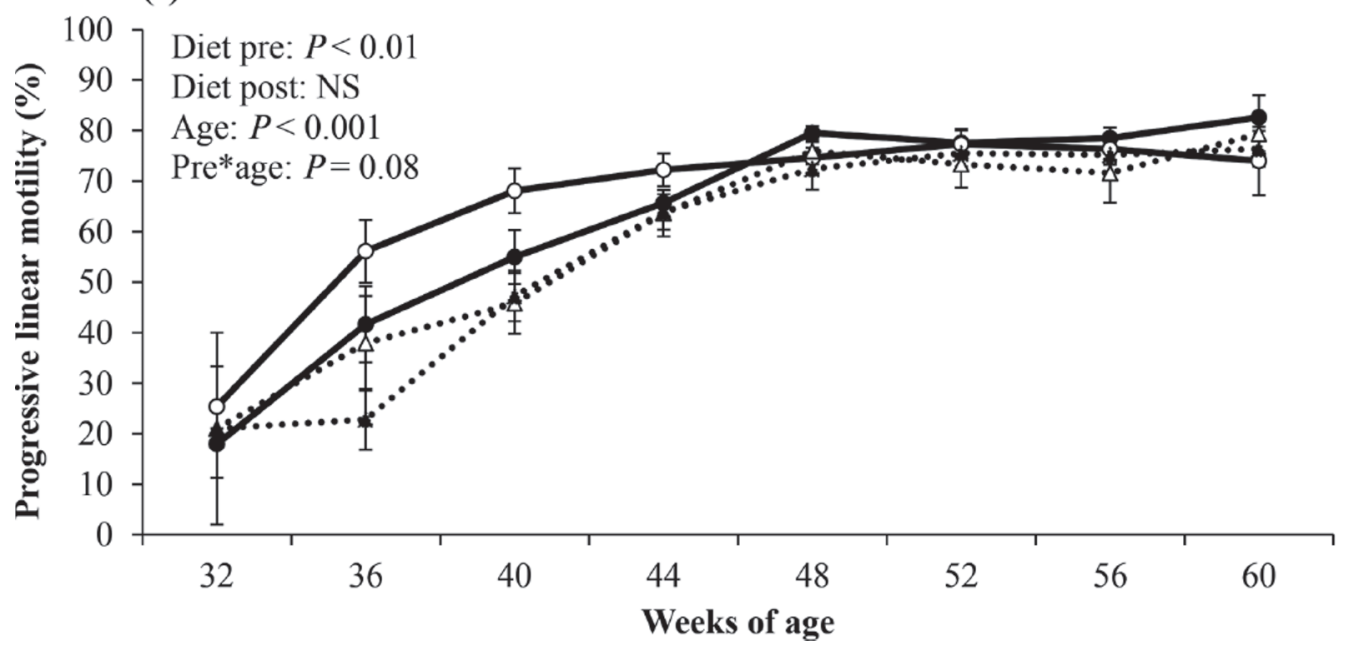

Figure 3. Effect of a high (Hi) or low (Lo) plane of nutrition offered pre- or post-6 mo of age on semen volume (a), total sperm number (b), and progressive linear motility (PLM; c) between 32 and 60 wk of age in Holstein-Friesian bulls (n = Hi-Hi: 19; Hi-Lo: 18; Lo-Lo: 22; Lo-Hi: $24)$. Values are mean \pm SEM. 
linked with increased LH secretion in cows (Amstalden et al., 2002). Any increases in adipose cell number in early life result from cell differentiation; such differentiation decreases with age and thus hypertrophy of adipocytes is more prevalent (Ailhaud et al., 1992; Cornelius et al., 1994). In accordance with this, Hi-Lo bulls had lower fat deposits post-6 mo than Hi-Hi bulls, indicating that hypertrophy was reduced when the diet was restricted. These 2 groups (Hi-Hi and Hi-Lo) were not different in age at puberty but did achieve puberty earlier than either Lo-Lo or Lo-Hi bulls.

Although the response of age at puberty onset to early life dietary manipulation has been reported previously in bulls (Brito et al., 2007c; Dance et al., 2015; Harstine et al., 2015), this is the first study using dairy bulls to report that effects of a reduction in ADG during early life cannot be overcome through subsequent realimentation. In agreement with the findings of the current study, Brito et al. (2007a) reported that the delay in puberty caused by restricting Angus and Angus $\times$ Charolais bulls from 10 to 26 wk could not be overcome by offering ad libitum concentrate after 26 wk of age, following a restricted diet $(75 \%$ of the intake of ad libitum fed controls) in early life. The importance of animal growth rate during the first 6 mo of life is highlighted further by the findings of Brito et al. (2012). In that study, bulls were weaned at 2.5 mo of age, maintained on a common management and dietary regimen from 2.5 to 6 mo of age, and subsequently offered a high, medium, or low plane consisting of 37, 14, or $0 \%$ concentrate, respectively, until 16 mo of age. The animals on the high feed allowance achieved an ADG of $1.6 \mathrm{~kg}$, which is similar to that achieved by $\mathrm{Hi}-\mathrm{Hi}$ and Lo-Hi bulls in the current study during the same period of development. Similar to our findings, a high ADG after 6 mo of age did not advance age at puberty in that study.

Although use of an artificial vagina (AV) allows for evaluation of bulls' libido and ability to mount (Barth et al., 2004), it requires training of the bulls (Parkinson, 2004). This training is neither practical nor safe in a research setting where there are a large number of bulls to collect from over a relatively short period. Collection via electro-ejaculation also has a greater guarantee of obtaining a semen sample than $\mathrm{AV}$, with collection via electro-ejaculation resulting in a semen sample being collected more consistently (Austin et al., 1961; Barth et al., 2004). Studies comparing semen collection by electro-ejaculation and AV have shown that ejaculates collected using electro-ejaculation have a higher volume but fewer sperm per milliliter (concentration) than ejaculates collected via an AV (Lorton et al., 1984; Rego et al., 2015). However, as volume and concentration are used to measure sperm output, there is normally no difference in total sperm number per ejaculate when the 2 methods are compared (Austin et al., 1961). As total sperm number is used for calculating age at puberty, either method is sufficient for defining the age at which an ejaculate with pubertal characteristics is produced.

The age at which sexual maturity was achieved was linked to age at puberty, with animals on the HPN before 6 mo of age achieving sexual maturity, on average, 4 wk ahead of their contemporaries offered the LPN. This earlier onset of sexual maturity is advantageous for the earlier collection of usable semen, particularly within the context of a seasonal production system with a short breeding season, as used in Ireland and other pasture-based regions. In contrast to our findings, despite observing differences in age at puberty in Holstein-Friesian bulls offered a low, medium, or high diet from 2 to 31 wk of age and using the same definition as used by the current study, Dance et al. (2016) reported no subsequent differences in age at sexual maturity. The interval between puberty and maturity was shorter in the current study (30 d) compared with the findings of Brito et al. (2012), where an interval of $50 \mathrm{~d}$ was observed for Angus and Angus $\times$ Charolais bulls; however, the standard error around the mean in that study suggests that our findings fall within a similar range.

From 4 to 10 mo of age, SST increased in bulls offered a high diet, indicating greater insulation of the testes and the effect of prevailing plane of nutrition. Kastelic et al. (1996) reported that insulation of the scrotal neck results in ejaculates containing a lower percentage of sperm with normal morphology. Additionally, it has been reported that whole-scrotum insulation of Bos indicus and Bos indicus $\times$ Bos taurus bulls reduced sperm production and quality (Brito et al., 2003). The greater SST observed in the current study suggests that offering a high plane of nutrition may affect temperature regulation in the testes. Maintenance of a testicular temperature between $2^{\circ} \mathrm{C}$ and $6^{\circ} \mathrm{C}$ lower than core body temperature is essential for normal spermatogenesis in bulls (Waites and Setchell, 1990). In contrast to our findings, feeding a high (concentrate) compared with a moderate (forage) energy diet did not affect average scrotal temperature in bulls (Coulter et al., 1997). In the aforementioned study, the authors reported a smaller gradient in bulls offered the high-energy diet, which is in contrast to our observation that bulls on the Hi diet had a larger gradient than their counterparts. Although infrared thermography does not directly examine the internal testicular temperature, a study of 9 rams showed that correlation coefficients between the temperature of a surrogate testis (water-filled balloon, 
inserted following removal of right testis) in the scrotum and scrotal surface temperature were 0.89 (Coulter et al., 1988). The authors concluded that infrared thermography could be used as a noninvasive method to characterize testicular temperature. Although there may be some confounding effects due to scrotal size, the greater scrotal fatness (thus, insulation) in animals on the Hi diet may impede heat radiation and thus not accurately reflect prevailing testicular temperature. It has been reported that feeding beef bulls a high energy ( $80 \%$ concentrate $+20 \%$ forage) diet after weaning leads to a reduction in sperm production and semen quality compared with bull on $100 \%$ forage, putatively as a result of increased fat deposited around the testes and thus increased testicular temperature impairing normal testicular function (Coulter et al., 1987). It has also been reported that bulls will deposit more fat around the testicular vascular cone as they get older (Brito et al., 2002); therefore, the bulls with increased scrotal fat depth may have excessive fat accumulation as they age. More recent work has reported that an ADG of $1.6 \mathrm{~kg} / \mathrm{d}$ in young beef bulls will not affect sperm production or semen quality (Brito et al., 2012). This finding is supported by our results using HolsteinFriesian bulls.

Studies in dairy bulls reported no improvement in sperm production potential or semen quality postpuberty when bulls were on HPN up to 31 wk of age (Harstine et al., 2015; Dance et al., 2016). Our findings agree with these results and highlight that continuation of the HPN from 6 mo of age up to and beyond puberty did not deleteriously affect either sperm production or semen quality after puberty, in the context of the current study. However, it is worth considering that prolonged feeding of high-energy diets may reduce semen quantity and quality due to disruptions in testicular thermoregulation, as discussed earlier. In both beef (Brito et al., 2007b) and dairy (Dance et al., 2015; Harstine et al., 2015) bulls, the paired testes weight was greater among bulls offered a high plane of nutrition up to $31 \mathrm{wk}$ of age; however, daily sperm production at 16 mo of age was unaffected by diet during the first $6 \mathrm{mo}$ of life. We observed similar findings in our study. Given that the number of sperm produced per gram of testicular parenchyma is apparently constant in bulls $\left(10-14 \times 10^{6}\right.$ sperm cells/g of parenchyma), daily sperm production should be dictated by paired testes weight (Macmillan and Hafs, 1968; Brito, 2014). The findings of the above studies, as well as our own, do not fully support this hypothesis. Testicular histology confirms that volume density of Sertoli cells was not affected by diet in the first 6 mo of life, at the time when Sertoli cell proliferation ceases (Attal et al.,
1963). The fact that diet did not affect Sertoli cell numbers during their proliferating phase explains why germ cell volume density is not affected before 6 mo during the first phase of the experiment or after 6 mo, when the number of Sertoli cells remains constant. The LPN diet did not influence the spermatogenic potential of animals during the first 6 mo of the experiment, which explains why total sperm number was not different during the postpubertal period (Figure 3) or why germ cell volume density was not different at slaughter (Table 4). Because the pre- 6 mo diet was associated with paired testes weight, the sperm production potential was greater in bulls that received the HPN diet early in life.

\section{CONCLUSIONS}

The data presented here clearly demonstrate that effects of dietary restriction in early life on timing of puberty onset cannot be overcome by enhancing plane of nutrition post- 6 mo of age. Moreover, advantages in terms of hastening onset of puberty by offering young bulls a high plane of nutrition in the first 6 mo of life will not be undone by imposing a moderate diet subsequently. Thus, a high plane of nutrition pre- 6 mo of age will hasten age at puberty, regardless of plane of nutrition post- 6 mo of age. However, this study suggests that the advantages gained in terms of earlier onset of puberty, sexual maturation, and availability of saleable semen do not extend to improvements in semen volume or quality once animals are sexually mature.

\section{ACKNOWLEDGMENTS}

We gratefully acknowledge support from the Irish Department of Agriculture, Food and the Marine under the Research Stimulus Fund (Project 11/S/116). The authors are grateful for the skilled technical assistance of P. Reilly (University College Dublin) for help with bomb calorimetry and Marie-Claire Blache (PIC, UMR0085 PRC, INRA, Nouzilly, France) for expert help regarding Image $J$ (version $1.51 \mathrm{~h}$, National Institutes of Health, Bethesda, MD) macro programming and software.

\section{REFERENCES}

Ailhaud, G., P. Grimaldi, and R. Negrel. 1992. Cellular and molecular aspects of adipose tissue development. Annu. Rev. Nutr. 12:207233

Amann, R. P. 1970. Sperm production rates. Pages 433-482 in The Testis. Vol. 1. A. D. Johnson, W. R. Gomes, and N. L. VanDemark, ed. Academic Press, New York, NY.

Amstalden, M., M. R. Garcia, R. L. Stanko, S. E. Nizielski, C. D. Morrison, D. H. Keisler, and G. L. Williams. 2002. Central infusion of recombinant ovine leptin normalizes plasma insulin and stimulates 
a novel hypersecretion of luteinizing hormone after short-term fasting in mature beef cows. Biol. Reprod. 66:1555-1561.

Attal, J., M. Courot, C. Richetin, and C. Pisselet. 1963. Développement testiculaire et établissement de la spermatogénèse chez le taureau. Pages 219-241 in Proc. Annales de Biologie Animale Biochimie Biophysique. EDP Sciences, Les Ulis, France.

Austin, J. W., E. W. Hupp, and R. L. Murphree. 1961. Comparison of quality of bull semen collected in the artificial vagina and by electroejaculation. J. Dairy Sci. 44:2292-2297.

Barth, A. D., A. A. Arteaga, L. F. Brito, and C. W. Palmer. 2004. Use of internal artificial vaginas for breeding soundness evaluation in range bulls: An alternative for electroejaculation allowing observation of sex drive and mating ability. Anim. Reprod. Sci. $84: 315-325$.

Barth, A. D., L. F. C. Brito, and J. P. Kastelic. 2008. The effect of nutrition on sexual development of bulls. Theriogenology 70:485-494.

Berry, D. P., E. Wall, and J. E. Pryce. 2014. Genetics and genomics of reproductive performance in dairy and beef cattle. Animal 8(Suppl. 1):105-121.

Brito, L. F. 2014. Applied andrology in cattle (Bos taurus). Pages 297-380 in Animal Andrology: Theories and Applications. P. J. Chenoweth and S. Lorton, ed. CABI, Wallingford, UK.

Brito, L. F., A. D. Barth, N. C. Rawlings, R. E. Wilde, D. H. Crews Jr., Y. R. Boisclair, R. A. Ehrhardt, and J. P. Kastelic. 2007a. Effect of feed restriction during calfhood on serum concentrations of metabolic hormones, gonadotropins, testosterone, and on sexual development in bulls. Reproduction 134:171-181.

Brito, L. F., A. D. Barth, N. C. Rawlings, R. E. Wilde, D. H. Crews Jr., P. S. Mir, and J. P. Kastelic. 2007b. Effect of improved nutrition during calfhood on serum metabolic hormones, gonadotropins, and testosterone concentrations, and on testicular development in bulls. Domest. Anim. Endocrinol. 33:460-469.

Brito, L. F., A. D. Barth, N. C. Rawlings, R. E. Wilde, D. H. Crews, P. S. Mir, and J. P. Kastelic. 2007c. Effect of nutrition during calfhood and peripubertal period on serum metabolic hormones, gonadotropins and testosterone concentrations, and on sexual development in bulls. Domest. Anim. Endocrinol. 33:1-18.

Brito, L. F., A. D. Barth, R. E. Wilde, and J. P. Kastelic. 2012. Effect of growth rate from 6 to 16 months of age on sexual development and reproductive function in beef bulls. Theriogenology 77:1398-1405.

Brito, L. F., A. E. Silva, R. T. Barbosa, M. M. Unanian, and J. P. Kastelic. 2003. Effects of scrotal insulation on sperm production, semen quality, and testicular echotexture in Bos indicus and Bos indicus x Bos taurus bulls. Anim. Reprod. Sci. 79:1-15.

Brito, L. F. C., A. E. D. F. Silva, L. H. Rodrigues, F. V. Vieira, L. A. G. Deragon, and J. P. Kastelic. 2002. Effect of age and genetic group on characteristics of the scrotum, testes and testicular vascular cones, and on sperm production and semen quality in AI bulls in Brazil. Theriogenology 58:1175-1186.

Brito, L. F. C., A. E. D. F. Silva, M. M. Unanian, M. A. N. Dode, R. T. Barbosa, and J. P. Kastelic. 2004. Sexual development in early- and late-maturing Bos indicus and Bos indicus $\times$ Bos taurus crossbred bulls in Brazil. Theriogenology 62:1198-1217.

Byrne, C. J., S. Fair, A. M. English, C. Urh, H. Sauerwein, M. A. Crowe, P. Lonergan, and D. A. Kenny. 2017. Effect of breed, plane of nutrition and age on growth, scrotal development, metabolite concentrations and on systemic gonadotropin and testosterone concentrations following a $\mathrm{GnRH}$ challenge in young dairy bulls. Theriogenology 96:58-68.

Byrne, C. J., S. Fair, A. M. English, C. Urh, H. Sauerwein, M. A Crowe, P. Lonergan, and D. A. Kenny. 2018. Plane of nutrition before and after 6 months of age in Holstein-Friesian bulls: II. Effects on metabolic and reproductive endocrinology and identification of physiological markers of puberty and sexual maturation. J. Dairy Sci. 101:3460-3475. https://doi.org/10.3168/jds.2017-13720.

Campion, B., M. Keane, D. Kenny, and D. Berry. 2009. Evaluation of estimated genetic merit for carcass weight in beef cattle: Live weights, feed intake, body measurements, skeletal and muscular scores, and carcass characteristics. Livest. Sci. 126:87-99.
Cardoso, R. C., B. R. Alves, L. D. Prezotto, J. F. Thorson, L. O. Tedeschi, D. H. Keisler, C. S. Park, M. Amstalden, and G. L. Williams. 2014. Use of a stair-step compensatory gain nutritional regimen to program the onset of puberty in beef heifers. J. Anim. Sci. 92:2942-2949.

Conroy, S., M. Drennan, D. Kenny, and M. McGee. 2010. The relationship of various muscular and skeletal scores and ultrasound measurements in the live animal, and carcass classification scores with carcass composition and value of bulls. Livest. Sci. 127:11-21.

Cornelius, P., O. A. MacDougald, and M. D. Lane. 1994. Regulation of adipocyte development. Annu. Rev. Nutr. 14:99-129.

Coulter, G. H., T. D. Carruthers, R. P. Amann, and G. C. Kozub. 1987. Testicular development, daily sperm production and epididymal sperm reserves in 15-mo-old Angus and Hereford bulls: effects of bull strain plus dietary energy. J. Anim. Sci. 64:254-260.

Coulter, G. H., R. B. Cook, and J. P. Kastelic. 1997. Effects of dietary energy on scrotal surface temperature, seminal quality, and sperm production in young beef bulls. J. Anim. Sci. 75:1048-1052.

Coulter, G. H., P. L. Senger, and D. R. C. Bailey. 1988. Relationship of scrotal surface temperature measured by infrared thermography to subcutaneous and deep testicular temperature in the ram. J. Reprod. Fertil. 84:417-423.

Dance, A., J. Thundathil, P. Blondin, and J. Kastelic. 2016. Enhanced early-life nutrition of Holstein bulls increases sperm production potential without decreasing postpubertal semen quality. Theriogenology 86:687-694.e2.

Dance, A., J. Thundathil, R. Wilde, P. Blondin, and J. Kastelic. 2015. Enhanced early-life nutrition promotes hormone production and reproductive development in Holstein bulls. J. Dairy Sci. 98:987998.

de Roos, A. P., C. Schrooten, R. F. Veerkamp, and J. A. van Arendonk. 2011. Effects of genomic selection on genetic improvement, inbreeding, and merit of young versus proven bulls. J. Dairy Sci 94:1559-1567.

Edwards, D. A., W. Hammond, M. Healy, J. Tanner, and R. Whitehouse. 1955. Design and accuracy of calipers for measuring subcutaneous tissue thickness. Br. J. Nutr. 9:133-143.

Falk, A. J., C. L. Waldner, B. S. Cotter, J. Gudmundson, and A. D. Barth. 2001. Effects of epidural lidocaine anesthesia on bulls during electroejaculation. Can. Vet. J. 42:116-120.

Harstine, B. R., M. Maquivar, L. A. Helser, M. D. Utt, C. Premanandan, J. M. DeJarnette, and M. L. Day. 2015. Effects of dietary energy on sexual maturation and sperm production in Holstein bulls. J. Anim. Sci. 93:2759-2766.

Holden, S. A., C. Murphy, J. F. Moreno, S. T. Butler, A. R. Cromie, P. Lonergan, and S. Fair. 2017. In vitro characterisation of fresh and frozen sex-sorted bull spermatozoa. Reprod. Fertil. Dev. 29:1415-1425.

Hornick, J. L., C. Van Eenaeme, O. Gérard, I. Dufrasne, and L. Istasse. 2000. Mechanisms of reduced and compensatory growth. Domest. Anim. Endocrinol. 19:121-132.

Johnson, L. 1985. Increased daily sperm production in the breeding season of stallions is explained by an elevated population of spermatogonia. Biol. Reprod. 32:1181-1190.

Kastelic, J. P. 2014. Understanding and evaluating bovine testes. Theriogenology 81:18-23.

Kastelic, J. P., R. B. Cook, G. H. Coulter, and R. G. Saacke. 1996. Insulating the scrotal neck affects semen quality and scrotal/testicular temperatures in the bull. Theriogenology 45:935-942.

Lorton, S. P., J. L. Winter, M. M. Pace, and J. J. Sullivan. 1984. Evaluation of two seminal collection regimens for mature Holstein bulls. J. Anim. Sci. 58:1-5.

Macmillan, K. L., and H. D. Hafs. 1968. Gonadal and extra gonada sperm numbers during reproductive development of Holstein bulls. J. Anim. Sci. 27:697-700.

Menegassi, S. R., J. O. Barcellos, E. A. Dias, C. Koetz Jr., G. R. Pereira, V. Peripolli, C. McManus, M. E. Canozzi, and F. G. Lopes. 2015. Scrotal infrared digital thermography as a predictor of seasonal effects on sperm traits in Braford bulls. Int. J. Biometeorol. 59:357-364 
NRC. 2001. Nutrient Requirements of Dairy Cattle. Page 408. 7th rev. ed. National Academies of Science, Washington, DC.

Palasz, A. T., W. F. Cates, A. D. Barth, and R. J. Mapletoft. 1994. The relationship between scrotal circumference and quantitative testicular traits in yearling beef bulls. Theriogenology 42:715-726.

Parkinson, T. J. 2004. Evaluation of fertility and infertility in natural service bulls. Vet. J. 168:215-229.

Rawlings, N., A. C. Evans, R. K. Chandolia, and E. T. Bagu. 2008. Sexual maturation in the bull. Reprod. Domest. Anim. 43(Suppl. 2):295-301.

Rego, J. P., A. A. Moura, A. S. Nouwens, M. R. McGowan, and G. B. Boe-Hansen. 2015. Seminal plasma protein profiles of ejaculates obtained by internal artificial vagina and electroejaculation in Brahman bulls. Anim. Reprod. Sci. 160:126-137.

Rodríguez-Sánchez, J. A., A. Sanz, C. Tamanini, and I. Casasus. 2015. Metabolic, endocrine, and reproductive responses of beef heifers submitted to different growth strategies during the lactation and rearing periods. J. Anim. Sci. 93:3871-3885.

Sweeney, R. A. 1989. Generic combustion method for determination of crude protein in feeds: collaborative study. J. Assoc. Off. Anal. Chem. 72:770-774.

Waites, G., and B. Setchell. 1990. Physiology of the mammalian testis. Pages 1-105 in Marshall's Physiology of Reproduction. Vol. 2. G. E. Lamming, ed. Churchill Livingstone. London, UK.

Wathes, D. C., G. E. Pollott, K. F. Johnson, H. Richardson, and J. S. Cooke. 2014. Heifer fertility and carry over consequences for life time production in dairy and beef cattle. Animal 8(Suppl 1):91-104.

Wolf, F. R., J. Almquist, and E. Hale. 1965. Prepuberal behavior and puberal characteristics of beef bulls on high nutrient allowance. J. Anim. Sci. 24:761-765. 